\title{
S-1 plus cisplatin versus fluorouracil plus cisplatin in advanced gastric or gastro-esophageal junction adenocarcinoma patients: a pilot study
}

\author{
Yuhong Li ${ }^{1, *}$, Miaozhen Qiu ${ }^{1,2, *}$, Jianming $X u^{3, *}$, Guoping Sun ${ }^{4}$, Huishan Lu ${ }^{5}$, Yunpeng \\ Liu ${ }^{6}$, Meizuo Zhong ${ }^{7}$, Helong Zhang ${ }^{8}$, Shiying $\mathrm{Yu}^{9}$, Wei $\mathrm{Li}^{10}$, Xiaohua $\mathrm{Hu}^{11}$, Jiejun \\ Wang ${ }^{12}$, Ying Cheng ${ }^{13}$, Juntian Zhou ${ }^{14}$, Zengqing Guo ${ }^{15}$, Zhongzhen Guan ${ }^{1}$ and \\ Ruihua $\mathbf{X u}^{1}$ \\ ${ }^{1}$ Department of Medical Oncology, Sun Yat-Sen University Cancer Center, State Key Laboratory of Oncology in South China, \\ Collaborative Innovation Center for Cancer Medicine, Guangzhou, China \\ 2 Department of Oncology, The Sidney Kimmel Comprehensive Cancer Center, The Johns Hopkins University School of \\ Medicine, Baltimore, MD, USA \\ ${ }^{3}$ Department of Oncology, 307 Hospital of the People's Liberation Army, Beijing, China \\ ${ }^{4}$ Department of Oncology, The First Affiliated Hospital of AnHui Medical University, Hefei, China \\ ${ }^{5}$ Department of General Surgery, Affiliated Union Hospital, Fujian Medical University, Fuzhou, China \\ ${ }^{6}$ The Second Lab of Cancer Research Institute, The First Hospital of China Medical University, Shenyang, China \\ 7 Department of Oncology, Xiangya Hospital, Central South University, Changsha, Hunan, China \\ ${ }^{8}$ Department of Oncology, Tangdu Hospital, The Fourth Military Medical University, Xi'an, China \\ ${ }^{9}$ Department of Oncology, Tongji Cancer Center, Tongji Hospital, Tongji Medical College, Huazhong University of Science and \\ Technology, Wuhan, China \\ ${ }^{10}$ Stem Cell and Cancer Center, First Affiliated Hospital, Jilin University, Changchun, Jilin, China \\ ${ }^{11}$ Department of Oncology, Affiliated Tumor Hospital of Guangxi Medical University, Nanning, China \\ 12 Department of Oncology, Changzheng Hospital, Shanghai, China \\ 13 Department of Oncology, Tumor Hospital of Jilin Province, Changchun, China \\ 14 Department of Oncology, Tumor Hospital of Hunan Province, Changsha, China \\ ${ }^{15}$ Department of Oncology, Tumor Hospital of Fujian Province, Fuzhou, China \\ * These authors have contributed equally to this work
}

Correspondence to: Ruihua XU, email: xurh@sysucc.org.cn

Keywords: gastric cancer, first-line chemotherapy, fluorouracil, S-1

Received: June 11,2015 Accepted: August 31,2015 Published: October 02, 2015

This is an open-access article distributed under the terms of the Creative Commons Attribution License, which permits unrestricted use, distribution, and reproduction in any medium, provided the original author and source are credited.

\section{ABSTRACT}

The safety and efficacy of S-1 plus cisplatin in Chinese advanced gastric cancer patients in first line setting is unknown. In this pilot study, patients with advanced gastric or gastro-esophageal junction adenocarcinoma were enrolled and randomly assigned in a 1:1 ratio to receive S-1 plus cisplatin (CS group) or 5-FU plus cisplatin (CF group). The primary endpoint was time to progression (TTP). Secondary end points included overall survival (OS) and safety. This study was registered on ClinicalTrials. Gov, number NCT01198392. A total of 236 patients were enrolled. Median TTP was 5.51 months in CS group compared with 4.62 months in CF group [hazard ratio (HR) $1.028,95 \%$ confidential interval (CI) $0.758-1.394, p=0.859$ ]. Median OS was 10.00 months and 10.46 months in CS and CF groups (HR 1.046, 95\%CI 0.709-1.543, $p=$ $0.820)$, respectively. The most common adverse events in both groups were anemia, leukopenia, neutropenia, nausea, thrombocytopenia, vomiting, anorexia and diarrhea. We find that S-1 plus cisplatin is an effective and tolerable option for advanced gastric or gastro-esophageal junction adenocarcinoma patients in China. 


\section{INTRODUCTION}

The incidence rate of gastric carcinoma varies dramatically worldwide and it is particularly high in Eastern Asia, especially in China [1]. Advanced gastric cancer (AGC) patients account for $40 \%$ of new Chinese gastric cancer patients and have a worse prognosis than that with early stage diseases [2]. Though first-line chemotherapy for AGC patients prolongs overall survival (OS) and improves quality of life (QoL) compared with best supportive care (BSC); the median survival for AGC patients who receive palliative chemotherapy is approximately 7 to 11 months [2-8].

The available cytotoxic agents for treatment of AGC patients included cisplatin, fluorouracil, oxaliplatin, irinotecan and taxane [3,9-12]. S-1 is one of the oral fluoropyrimidines, consisting of tegafur, 5-chloro-2, 4-dihydropyrimidine, and potassium oxonate $[13,14]$. Data from two phase II studies of single agent S-1 showed a response rate of $45 \%$ and 2-year survival of $17 \%$, in association with $5 \%$ or lower frequencies of grade 3 or 4 toxic effects $[15,16]$.

Ajani JA et al. compared cisplatin/S-1 (CS) and cisplatin/5-fluorouracil (CF) in the first-line chemotherapy of AGC in a non-inferiority setting (FLAGS) and they found that CS was non-inferior to $\mathrm{CF}$ with a lesser toxicity profile [17]. However, the 'lesser toxicity' observed in this trial was arguable, as a lower dose of cisplatin was used in CS group, and actually this trial failed to gain regulatory approval of S-1 in USA.

For any new agent, confirmation that efficacy and toxicity profiles are similar in non-Chinese and Chinese patients is important, given evidence of differences in treatment effects between populations with some agents (e.g. the gefitinib, which has a different toxicity profile in Asian and Western populations [18]).

Besides, Jin $\mathrm{M}$ et al. used S-1 monotherapy as second-line chemotherapy in AGC patients who had previously treated with cisplatin/ infusional fluorouracil and they found that S-1 monotherapy provided mild response rate and overall survival (OS) as well as favorable toxicity profile in the second-line setting for AGC patients [19].

In this study, we compared the effect of CS and CF in the first-line treatment for Chinese AGC patients, using the domestic agent of S-1 (produced by Shenzhen Wanle Pharmacy Company). This study was designed in 2008, before the publication of FLAGS study.

\section{RESULTS}

\section{Patient characteristics}

Between October 2008 and June 2011, 255 patients were randomly assigned to either CS or CF group at 15 centers in China. The observation profile was listed in Figure 1.

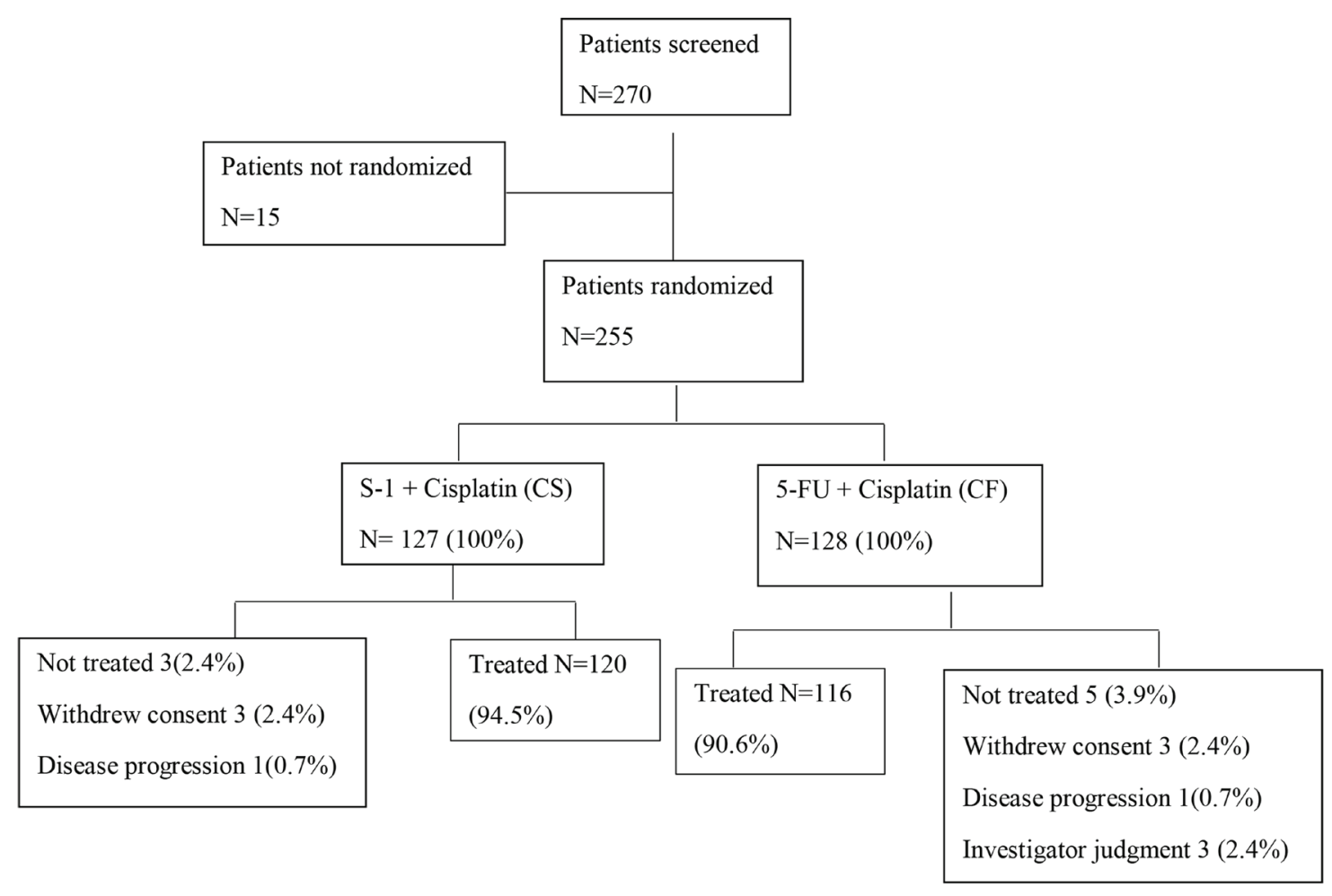

Figure 1: CONSORT diagram. 
Table 1: Baseline characteristics.

\begin{tabular}{|c|c|c|c|}
\hline Features & S1+Cisplatin (\%) & 5Fu+Cisplatin (\%) & $P$ value \\
\hline \multicolumn{4}{|l|}{ Age } \\
\hline Mean \pm SD & $53.27 \pm 12.14$ & $55.33 \pm 11.16$ & 0.177 \\
\hline \multicolumn{4}{|l|}{ Gender } \\
\hline Male & $84(70.0)$ & $85(73.3)$ & \\
\hline Female & $36(30.0)$ & $31(26.7)$ & 0.577 \\
\hline \multicolumn{4}{|l|}{ Race } \\
\hline Han & $116(96.7)$ & $111(95.7)$ & \\
\hline Others & $4(3.3)$ & $5(4.3)$ & 0.695 \\
\hline \multicolumn{4}{|l|}{ Histology } \\
\hline Low differentiated & $57(47.5)$ & $65(56.0)$ & \\
\hline Moderate differentiated & $28(23.3)$ & $17(14.7)$ & \\
\hline High differentiated & $2(1.7)$ & $5(4.3)$ & \\
\hline Others & $33(27.5)$ & $29(25.0)$ & 0.190 \\
\hline \multicolumn{4}{|l|}{ Location } \\
\hline Stomach & $70(58.33 \%)$ & $73(62.93 \%)$ & \\
\hline GE junction & $22(18.33 \%)$ & $10(8.62 \%)$ & \\
\hline Stomach and GE junction & $28(23.33 \%)$ & $33(28.45 \%)$ & 0.086 \\
\hline \multicolumn{4}{|l|}{ Sites of metastasis } \\
\hline 1 & $18(15.00 \%)$ & $18(15.52 \%)$ & \\
\hline$>1$ & $102(85.00 \%)$ & $98(84.48 \%)$ & 0.912 \\
\hline \multicolumn{4}{|l|}{ Previous gastrectomy } \\
\hline Yes & $65(54.17 \%)$ & $64(55.17 \%)$ & \\
\hline No & $55(45.83 \%)$ & $52(44.83 \%)$ & 0.877 \\
\hline \multicolumn{4}{|l|}{ PS } \\
\hline 0 & $28(23.33 \%)$ & $29(25.00 \%)$ & \\
\hline 1 & $85(70.83 \%)$ & $83(71.55 \%)$ & \\
\hline 2 & $7(5.83 \%)$ & $4(3.45 \%)$ & 0.673 \\
\hline
\end{tabular}

SD: Standard deviation; GE: Gastroesophageal; PS: Performance status

Of the 255 patients, 236 was allocated to receive at least one cycle of CS $(n=120)$ or CF $(n=116)$. Table 1 showed demographics and baseline characteristics of patients included in the analysis. The basic features were well balance between these two groups. About $50 \%$ of the patients had low differentiated cancer. Approximately $85 \%$ of the patients had more than one site of metastasis and over half of the patients received previous gastrectomy.

\section{Efficacy}

The mean dose intensity of S-1 and Fluorouracil was $278.46 \mathrm{mg} / \mathrm{m}^{2} /$ week and $964.48 \mathrm{mg} / \mathrm{m}^{2} /$ week respectively. The median cycles and duration of treatment in these two groups were 3.53 and $3.46(p=0.78), 4.03$ and 2.87 months $(p=0.0002)$, respectively.

Median time to progression (TTP) in CS and CF groups was 5.51 months [95\% confidence interval (CI): 4.59-6.26] versus 4.62 months (95\% CI: 4.00-6.33), hazard ratio $(\mathrm{HR}) 1.028,95 \%$ CI $0.76-1.39, p=0.86$,
Figure 2. There was no difference of median TTP among the three stratification factors (Table 2). The response rate was $22.5 \%$ [27 patients got a partial response (PR)] in CS group and $21.6 \%$ in $\mathrm{CF}$ group [2 complete response (CR) and $23 \mathrm{PR}$ ], $p=0.86$. The OS between these two groups was showed in Figure 3. The median OS for patients in CS and $\mathrm{CF}$ group was 10.00 months(95\% CI: 8.59-14.52)and 10.46 months (95\% CI: 8.92-13.84), $p=0.82$.

\section{Safety}

No significant difference in the overall rate of adverse events between these two groups was detected (all grades, Table 3). Anemia, neutropenia, nausea, thrombocytopenia, vomiting and anorexia were the most frequently reported adverse events. Patients assigned to CS group had slightly higher rates of thrombocytopenia, abdominal pain, hyperbilirubinemia, pigmentation and stomatitis than did patients assigned to CF group.

Patients in CS group had higher incidence rate of 
Table 2: Stratification factors

\begin{tabular}{|c|c|c|c|c|c|c|c|}
\hline & & & Number (\%) & $P *$ value & mTTP (months) & $95 \% \mathrm{CI}$ & $P^{\#}$ value \\
\hline \multirow{6}{*}{ PS } & \multirow{2}{*}{0} & CS group & $28(23.33 \%)$ & \multirow{6}{*}{0.57} & 5.54 & $4.33-8.16$ & \multirow[b]{2}{*}{0.87} \\
\hline & & CF group & $29(25.00 \%)$ & & 4.20 & $2.75-10.46$ & \\
\hline & \multirow{2}{*}{1} & CS group & $85(70.83 \%)$ & & 5.64 & \begin{tabular}{|l|}
$4.20-6.30$ \\
\end{tabular} & \multirow[b]{2}{*}{0.64} \\
\hline & & CF group & $83(71.55 \%)$ & & 5.05 & $4.00-6.56$ & \\
\hline & \multirow[b]{2}{*}{2} & CS group & \begin{tabular}{|l}
$7(5.84 \%)$ \\
\end{tabular} & & 4.41 & $3.39-5.62$ & \multirow[b]{2}{*}{0.84} \\
\hline & & CF group & $4(3.45 \%)$ & & 4.61 & $3.36-5.20$ & \\
\hline \multirow{4}{*}{$\begin{array}{l}\text { Numbers of } \\
\text { metastasis }\end{array}$} & \multirow[b]{2}{*}{1} & CS group & $18(15.00 \%)$ & \multirow{4}{*}{0.91} & 6.26 & $3.61-8.52$ & \multirow[b]{2}{*}{0.2} \\
\hline & & CF group & $18(15.52 \%)$ & & 5.64 & $4.00-6.26$ & \\
\hline & \multirow{2}{*}{$>1$} & CS group & $102(85.00 \%)$ & & 5.25 & $4.33-6.26$ & \multirow[b]{2}{*}{0.63} \\
\hline & & CF group & $98(84.48 \%)$ & & 4.33 & $3.90-5.87$ & \\
\hline \multirow{4}{*}{ Gastrectomy } & \multirow{2}{*}{ No } & CS group & $65(54.17 \%)$ & \multirow{4}{*}{0.88} & 5.25 & $4.23-6.26$ & \multirow[b]{2}{*}{0.86} \\
\hline & & CF group & $64(55.17 \%)$ & & 4.20 & $3.90-6.10$ & \\
\hline & \multirow[b]{2}{*}{ Yes } & CS group & $55(45.83 \%)$ & & 5.77 & $4.33-7.57$ & \multirow[b]{2}{*}{0.95} \\
\hline & & CF group & $52(44.83 \%)$ & & 5.05 & $3.70-9.97$ & \\
\hline
\end{tabular}

TTP: Time to progression

CS: cisplatin and S-1; CF: cisplatin and fluorouracil

*The comparison of patients in different stratification factors

\# The comparison of TTP for patients in CS and CF groups.

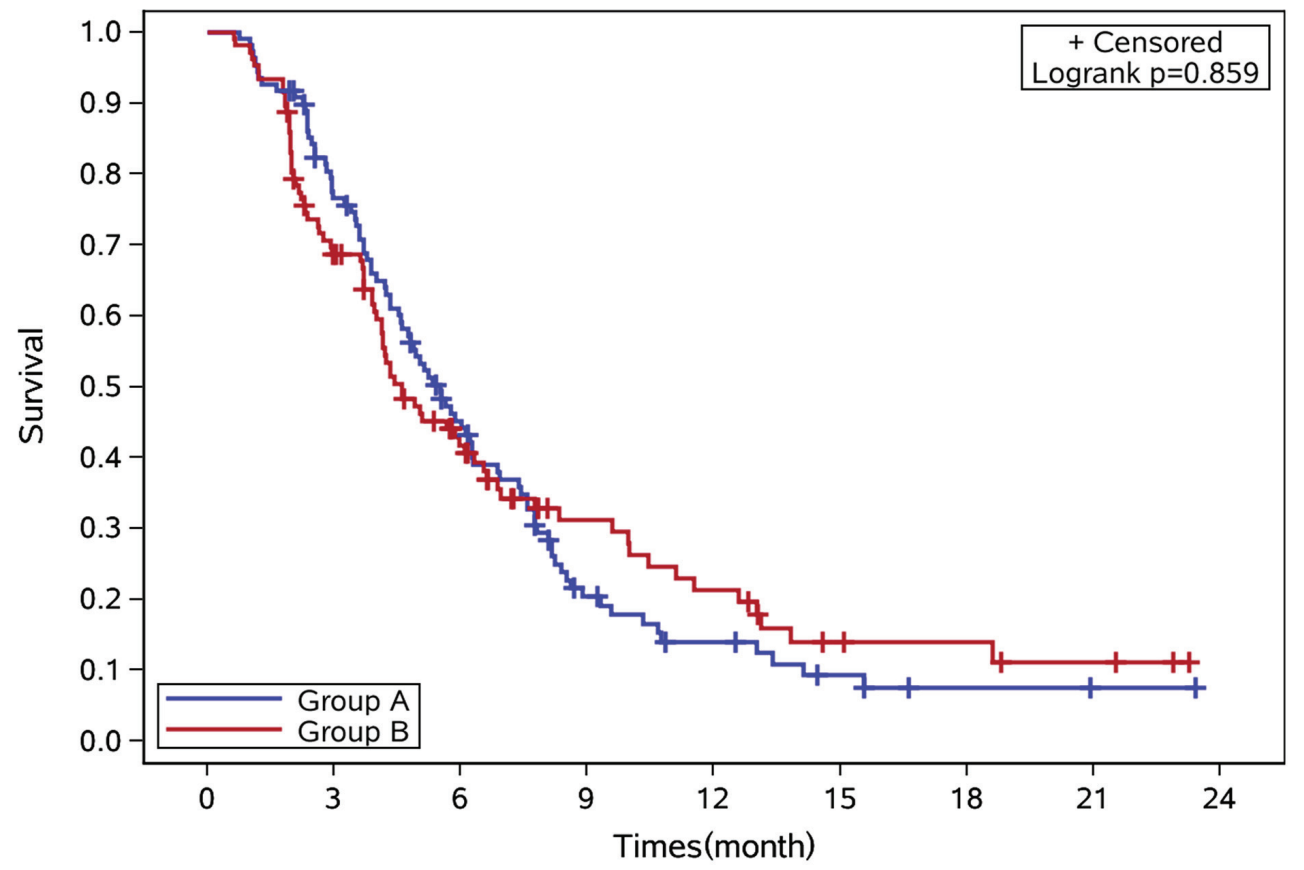

Number at risk:

\begin{tabular}{llllllllll|} 
Group A & 109 & 80 & 44 & 17 & 10 & 5 & 2 & 1 & 0 \\
Group B & 107 & 70 & 36 & 19 & 13 & 6 & 5 & 3 & 0 \\
\cline { 2 - 9 } & & &
\end{tabular}

Events:

\begin{tabular}{|c|c|c|c|c|c|c|c|c|c|}
\hline Group A & 0 & 25 & 32 & 23 & 5 & 3 & 1 & 0 & 0 \\
\hline Group B & 0 & 33 & 26 & 8 & 6 & 4 & 0 & 1 & 0 \\
\hline
\end{tabular}

Figure 2: Kaplan-Meier curves of time to progression in these two groups of patients. Group A: CS group. Group B: CF group. 
Table 3: Adverse event in our study compared with the FLAGS study

\begin{tabular}{|l|l|l|l|l|l|l|l|l|}
\hline & \multicolumn{3}{l}{ S-1plus cisplatin } & \multicolumn{3}{l}{ 5-FU plus cisplatin } \\
\cline { 2 - 9 } & Our result (\%) & \multicolumn{2}{l|}{ FLAGS Study (\%) } & \multicolumn{2}{l|}{ Our result (\%) } & \multicolumn{2}{l|}{ FLAGS Study (\%) } \\
\cline { 2 - 9 } & All & Grade 3/4 & All & Grade 3/4 & All & \multicolumn{2}{l|}{ Grade 3/4 } & \multicolumn{2}{l|}{ All } & Grade 3/4 \\
\hline Neutropenia & 68.6 & 36.4 & 28.6 & 18.6 & 55.9 & 13.6 & 47.2 & 40.0 \\
\hline Anemia & 80.2 & 25.6 & 44.0 & 15.7 & 72.0 & 11.9 & 46.1 & 19.3 \\
\hline Leucopenia & 71.9 & 17.6 & 17.5 & 7.3 & 62.7 & 5.9 & 23.0 & 13.8 \\
\hline Thrombocytopenia & 44.6 & 14.1 & 17.7 & 5.4 & 26.3 & 4.2 & 22.8 & 8.5 \\
\hline Diarrhea & 24.0 & 5.8 & 29.2 & 4.8 & 17.8 & 1.7 & 38.4 & 4.5 \\
\hline Vomiting & 43.0 & 4.1 & 48.0 & 7.9 & 42.4 & 5.1 & 55.3 & 9.6 \\
\hline Nausea & 50.4 & 3.3 & 61.6 & 7.5 & 60.2 & 4.2 & 67.3 & 9.6 \\
\hline Anorexia & 38.0 & 2.5 & 31.5 & 6.0 & 41.5 & 3.4 & 34.8 & 5.5 \\
\hline Constipation & 20.7 & 0 & $/$ & $/$ & 22.0 & 0.9 & $/$ & $/$ \\
\hline Abdominal pain & 15.7 & 1.7 & 25.1 & 7.3 & 5.9 & 0 & 22.4 & 5.3 \\
\hline Fatigue & 21.5 & 0 & 39.3 & 12.3 & 22.0 & 0 & 39.4 & 13.2 \\
\hline $\begin{array}{l}\text { Abnormal } \\
\text { pigmentation }\end{array}$ & 10.7 & 0 & $/$ & $/$ & 1.7 & 0 & $/$ & $/$ \\
\hline Hypokalemia & 4.1 & 0 & 6.9 & 3.6 & 4.2 & 0.9 & 16.7 & 10.8 \\
\hline Dehydration & $/$ & $/$ & 12.1 & 4.8 & $/$ & $/$ & 15.6 & 7.5 \\
\hline Weight loss & 0.8 & 0 & 28.4 & 4.0 & 0 & 0 & 32.3 & 6.1 \\
\hline Stomatitis & 3.3 & 0.8 & 6.3 & 1.3 & 6.8 & 0.9 & 30.1 & 13.6 \\
\hline
\end{tabular}

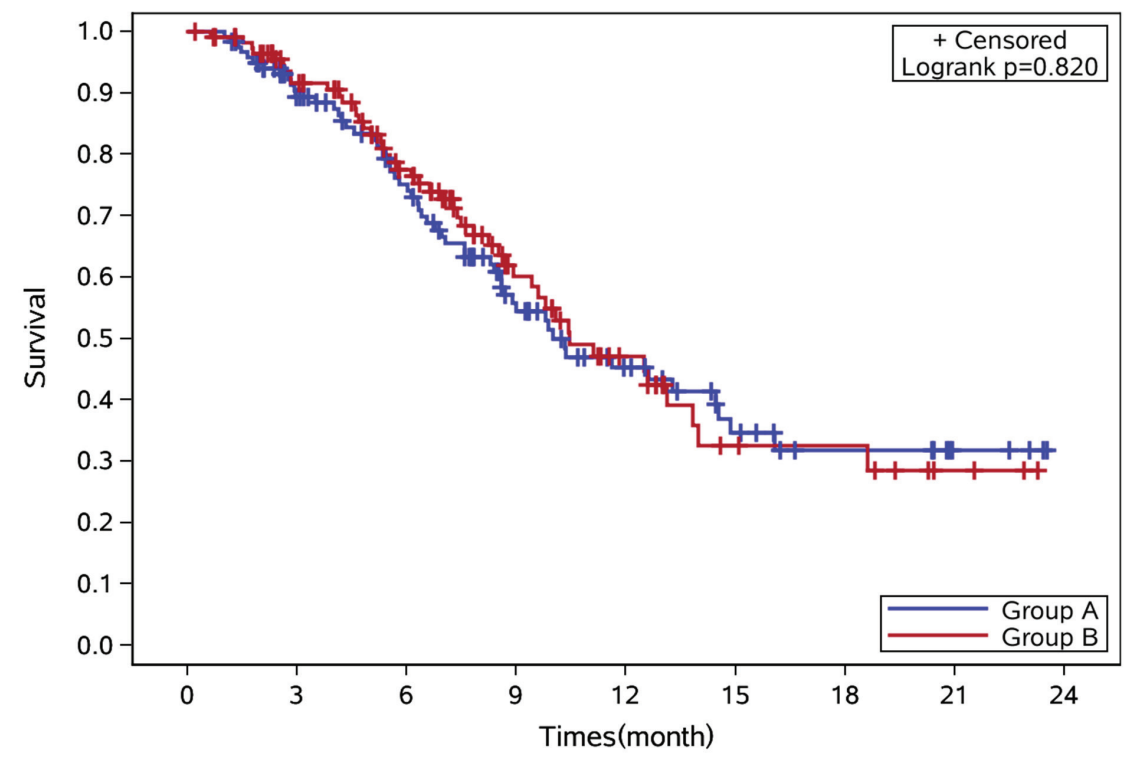

Number at risk:

\begin{tabular}{lllllllllll|}
\hline Group A & 120 & 94 & 72 & 41 & 26 & 15 & 9 & 4 & 0 \\
Group B & 116 & 94 & 66 & 34 & 20 & 9 & 8 & 3 & 0 \\
\hline
\end{tabular}

Events:

\begin{tabular}{|c|c|c|c|c|c|c|c|c|c|}
\hline Group A & 0 & 12 & 14 & 18 & 6 & 5 & 1 & 0 & 0 \\
\hline Group B & 0 & 9 & 13 & 12 & 7 & 5 & 0 & 1 & 0 \\
\hline
\end{tabular}

Figure 3: Kaplan-Meier curves of overall survival in these two groups of patients. Group A: CS group. Group B: CF group. 
grade 3 or 4 adverse events (Table 3 ). Serious adverse events (grade 3 or 4 adverse events) were reported in $73(60 \%)$ patients in CS group and 47 (36\%) patients in $\mathrm{CF}$ group, $p=0.0015$. The most common grade 3 or 4 adverse events were neutropenia, anemia, leucopenia and thrombocytopenia in CF-treated patients.

The proportion of patients reporting an adverse event that led to dose modifications or interruptions did not differ between these two groups. No drug related death in both groups was reported in our study.

\section{DISCUSSION}

Our findings showed that CS had comparable treatment effect with $\mathrm{CF}$, with respect to similar results of TTP, RR and OS. Patients assigned to S- 1 had a 0.9 month longer TTP than those allocated to a continuous infusion of fluorouracil. These findings for S-1 were consistent with the previous reports $[5,15]$. Drug development for gastric cancer has been focused on replacement of intravenous fluorouracil with oral agents $[4,20]$. Taken together with our findings, S-1 can be an alternative option for continuous infusion of fluorouracil in China.

Toxic effects of S-1 have been reported to be more severe in individuals from USA than those from Asian, indicating different dosage recommended for these populations $[13,21]$. Since similar discrepancies in toxic effects have been noted with tegafur and uracil, ethnic variations seem to be a factor with these dihydropyrimidine dehydrogenase inhibitory fluoropyrimidines [22]. In 2008, an American Society of Clinical Oncology (ASCO) abstract showed that S-1 plus cisplatin was superior to continuous infusion of fluorouracil plus cisplatin. Outside Asia, despite differences in dose and schedule of S-1 from Asian trials, S-1 plus cisplatin was associated with fewer toxic effects, slightly better survival, and non-inferiority compared with fluorouracil plus cisplatin [5]. In our study, no significant difference in the overall rate of adverse events between CS and CF groups was found. Despite a higher rate of grade 3 or 4 adverse events in CS group than in CF group, the number of patients discontinuing treatment due to toxicity was limited, and patients in CS group were able to stay on treatment longer than those in CF group. The most common grade 3 or 4 adverse events was hemorrhage. Early and effective prophylaxis as well as management of adverse events were helpful to ensure that patients would remain on the treatment.

The two treatment regimens were different in terms of cycle length: 5 weeks in CS group and 4 weeks in CF group. It seemed that the treatment duration was biased from the beginning favoring the experimental arm. However, patients in these two groups received the scans with the same frequency, every 8 weeks. This could eliminate the potential bias from different cycle lengths. There were different dose schedules for S1, including one week on one week off, two weeks on two weeks off, two weeks on one week off, four weeks on two weeks off and three weeks on two weeks off $[5,13,15-17,23$ 25]. There was no study to compare the difference among these different dose schedules in efficacy and safety. It is reasonable to assume that longer off time would produce less side effect and that is why we pick up the dose schedule of 3 weeks on and two weeks off. We confirmed that this dose schedule was tolerable in Chinese AGC patients.

Oxaliplatin which has potentially improved efficacy and tolerance for platinum-based chemotherapy in AGC patients, has been widely used in the treatment of advanced gastric cancer $[4,8,26]$. However, cisplatin combined with fluorouracil was considered as the standard treatment for control group, the aim of our study was to make a direct comparison between S-1 and fluorouracil, so we chose cisplatin in both groups while not oxaliplatin.

In conclusion, we found that S-1 plus cisplatin was comparable to fluorouracil plus cisplatin, with a similar TTP and tolerable toxicity. In China, central venous catheterization or peripherally inserted central catheterization (PICC) would be established for patients to receive continuous infusion of $5 \mathrm{Fu}$, but unnecessary for administration of cisplatin. With the advantage of oral administration, patients in S-1 group avoided the venous port. Based on our finding, S-1 plus cisplatin, was an acceptable substitute for infusion 5-FU plus cisplatin and an appropriate option as first-line chemotherapy for advanced gastric cancer patients in China. This pilot study provides some basic information for the further phase III clinical study for S1 in China.

\section{MATERIALS AND METHODS}

\section{Patient enrollment}

During October 2008 and June 2011, we prospectively recruited AGC patients all over China. Patients were enrolled based on the following criteria: 1) Men or women, aging between 18 and 75 years old; 2) Histologically confirmed inoperable locally advanced, recurrent, or metastatic adenocarcinoma of the stomach or gastro-esophageal junction; 3) Eastern Cooperative Oncology Group (ECOG) performance status (PS) 0-2; 4) Adequate organ function and measurable diseases; 5) At least one measurable lesion with a diameter $\geq 20$ mm using conventional Computed Tomography (CT) or Magnetic Resonance Imaging (MRI) scans or $\geq 10 \mathrm{~mm}$ using spiral CT scans; 6) A life expectancy of at least 3 months.

The exclusion criteria included: 1) Pregnant or lactating women or women of childbearing potential with positive pregnancy test at baseline. Postmenopausal women with amenorrhea for at least 12 months to be 
considered of non-childbearing potential; 2) No target lesion; 3) No CT evaluation; 4) Prior systemic therapy for advanced or metastatic disease (for instance, cytotoxic chemotherapy or history of another malignancy within the last five years except cured basal cell carcinoma of skin and cured carcinoma in-situ of uterine cervix. active/ passive immunotherapy); 5) History or evidence upon physical examination of central nervous system diseases (for example, primary brain tumor, seizure not controlled with standard medical therapy, or any brain metastases); 6)Severe comorbidities including angina, intestinal obstruction, diarrhea and active gastrointestinal bleeding.

\section{Ethics statement}

All patients provided written informed consent. Approvals for the study protocol (and any modifications thereof) were obtained from independent ethics committees. The study was undertaken in accordance with the ethical standards of the World Medical Association Declaration of Helsinki. This study was registered on ClinicalTrials. Gov, number NCT01198392.

\section{Treatments}

Patients who satisfied all eligibility criteria were randomly assigned in a 1:1 ratio to receive $\mathrm{S} 1$ (Shenzhen Wanle Pharmaceutical Co., Ltd. China) plus cisplatin (CS group) or fluorouracil plus cisplatin (CF group). As a pilot study, there is no need for sample size calculation. We planned to enroll 270 patients.

Randomized grouping information for each patient was generated by central randomization system. At randomization, patients were stratified by ECOG PS (0-1 vs. 2), numbers of metastasis sites $(1 v s .>1)$ and gastrectomy (yes vs no). Neither patients nor investigators were masked to treatment assignment in this open-label study.

S-1 was given as $40 \mathrm{mg} / \mathrm{m}^{2}$ twice daily on day $1-21$ and cisplatin was $20 \mathrm{mg} / \mathrm{m}^{2}$ ivdrip on day $1-4$, repeated every 5 weeks in the CS group. In the CF group, 5-Fu was given as $800 \mathrm{mg} / \mathrm{m}^{2} / \mathrm{d} \mathrm{CI} 120 \mathrm{~h}$, and the dosage of cisplatin was $20 \mathrm{mg} / \mathrm{m}^{2}$ iv on day $1-4$, repeated every 4 weeks. The treatment would continue until disease progression, unacceptable toxicity, and withdrawal of consent or 6 cycles. Infusion treatment would be administrated in the inpatient department. Chemotherapy dose adjustments were allowed. Crossover to the other group at the time of disease progression was not allowed.

The primary endpoint was time to progression (TTP), defined as time from randomization until disease progression (PD) or death from any cause. Secondary endpoint included overall survival (OS) and safety. Investigators assessed tumor response and progression every 8 weeks, either radiologically using Response
Evaluation Criteria in Solid Tumors (RECIST) version 1.1 or clinically if a patient could not have radiological examination. Patients were followed up until death, loss to follow-up or end of study. Efficacy and safety data were monitored by an independent data monitoring committee. Adverse events were assessed according to the National Cancer Institute Common Terminology Criteria for Adverse Events (NCI-CTCAE) version 3.0 and serious adverse events according to International Conference on Harmonization guidelines.

\section{Treatment assessments}

CT scans of the chest, abdomen and pelvic were performed for tumor assessment 2 weeks before and repeated repeated every 8 weeks during the treatment. After the treatment, patients were recommended to receive the CT scans every 3 months. All patients in this study had full information of follow-up. The last date of follow-up was June 1st, 2014.

\section{Statistical analysis}

The intention-to-treat (ITT) principle was applied. All statistical analysis was performed by Statistical Package of Social Sciences 16.0 software. TTP was adjusted for stratification factors. Patient characteristics were described using summary statistics. $P$ value for comparing patient characteristics was calculated using chi squared test. Statistical significance was set at twosided $P<0.05$. All efficacy analysis were done on the full population. No imputation was made for missing assessments. Safety analysis included patients who received at least one dose of study medication.

\section{ACKNOWLEDGMENTS}

This study was supported mainly by grants-in-aid for cancer research from the Shenzhen Wanle Pharmacy Company. The sponsor had no role in the design of the study and provided support staff to ensure good clinical practice compliance. The sponsor and representative had the right to review the manuscript but had no authority to change any aspect of it.

\section{CONFLICTS OF INTEREST}

All authors declared that there is no conflict of interest.

\section{GRANT SUPPORT}

This work was supported by:

1. The third outstanding young talents training plan 
of Sun Yat-sen University cancer center.

2. Medical Scientific Research of Guangdong province B2014161.

3. Scientific and Technological projects of Guangdong Esophageal Cancer Institute Q201408.

\section{REFERENCES}

1. Moore MA, Eser S, Igisinov N, Igisinov S, Mohagheghi MA, Mousavi-Jarrahi A, Ozenturk G, Soipova M, Tuncer M, Sobue T. Cancer epidemiology and control in NorthWestern and Central Asia - past, present and future. Asian Pac J Cancer Prev. 2010; 11 Suppl 2: 17-32.

2. Qiu MZ, Wang ZQ, Zhang DS, Liu Q, Luo HY, Zhou $\mathrm{ZW}$, Li YH, Jiang WQ, Xu RH. Comparison of 6th and 7th AJCC TNM staging classification for carcinoma of the stomach in China. Ann Surg Oncol. 2011; 18: 1869-1876.

3. Cullinan SA, Moertel CG, Fleming TR, Rubin JR, Krook JE, Everson LK, Windschitl HE, Twito DI, Marschke RF, Foley JF, et al. A comparison of three chemotherapeutic regimens in the treatment of advanced pancreatic and gastric carcinoma. Fluorouracil vs fluorouracil and doxorubicin vs fluorouracil, doxorubicin, and mitomycin. Jama. 1985; 253: 2061-2067.

4. Cunningham D, Starling N, Rao S, Iveson T, Nicolson M, Coxon F, Middleton G, Daniel F, Oates J, Norman AR. Capecitabine and oxaliplatin for advanced esophagogastric cancer. N Engl J Med. 2008; 358: 36-46.

5. He MM, Wu WJ, Wang F, Wang ZQ, Zhang DS, Luo HY, Qiu MZ, Wang FH, Ren C, Zeng ZL, Xu RH. S-1-based chemotherapy versus capecitabine-based chemotherapy as first-line treatment for advanced gastric carcinoma: a metaanalysis. PLoS One. 2013; 8: e82798.

6. Park YH, Lee JL, Ryoo BY, Ryu MH, Yang SH, Kim BS, Shin DB, Chang HM, Kim TW, Yuh YJ, Kang YK. Capecitabine in combination with Oxaliplatin (XELOX) as a first-line therapy for advanced gastric cancer. Cancer Chemother Pharmacol. 2008; 61: 623-629.

7. Qiu MZ, Li Q, Wang ZQ, Liu TS, Liu Q, Wei XL, Jin Y, Wang DS, Ren C, Bai L, Zhang DS, Wang FH, Li YH et al. HER2-positive patients receiving trastuzumab treatment have a comparable prognosis with HER2-negative advanced gastric cancer patients: a prospective cohort observation. Int J Cancer. 2014; 134: 2468-2477.

8. Qiu MZ, Wei XL, Zhang DS, Jin Y, Zhou YX, Wang DS, Ren C, Bai L, Luo HY, Wang ZQ, Wang FH, Li YH, Yang DJ et al. Efficacy and safety of capecitabine as maintenance treatment after first-line chemotherapy using oxaliplatin and capecitabine in advanced gastric adenocarcinoma patients: a prospective observation. Tumour Biol. 2014; 35: 43694375 .

9. Bittoni A, Scartozzi M, Giampieri R, Faloppi L, Bianconi M, Mandolesi A, Del Prete M, Pistelli M, Cecchini L, Bearzi I, Cascinu S. Clinical evidence for three distinct gastric cancer subtypes: time for a new approach. PLoS
One. 2013; 8: e78544.

10. Kang EJ, Im SA, Oh DY, Han SW, Kim JS, Choi IS, Kim JW, Kim YJ, Kim JH, Kim TY, Lee JS, Bang YJ, Lee KW. Irinotecan combined with 5-fluorouracil and leucovorin third-line chemotherapy after failure of fluoropyrimidine, platinum, and taxane in gastric cancer: treatment outcomes and a prognostic model to predict survival. Gastric Cancer. 2013; 16: 581-589.

11. Kaya AO, Coskun U, Gumus M, Dane F, Ozkan M, Isikdogan A, Alkis N, Buyukberber S, Yumuk F, Budakoglu B, Demirci U, Berk V, Bilici A et al. The efficacy and toxicity of irinotecan with leucovorin and bolus and continuous infusional 5-fluorouracil (FOLFIRI) as salvage therapy for patients with advanced gastric cancer previously treated with platinum and taxane-based chemotherapy regimens. J Chemother. 2012; 24: 217-220.

12. Park SC, Chun HJ. Chemotherapy for advanced gastric cancer: review and update of current practices. Gut Liver. 2013; 7: 385-393.

13. Ajani JA, Faust J, Ikeda K, Yao JC, Anbe H, Carr KL, Houghton M, Urrea P. Phase I pharmacokinetic study of S-1 plus cisplatin in patients with advanced gastric carcinoma. $\mathrm{J}$ Clin Oncol. 2005; 23: 6957-6965.

14. Xu RH, Teng KY. [Progress in chemotherapy for advanced gastric cancer]. Ai Zheng. 2009; 28: 1108-1113.

15. Koizumi W, Narahara H, Hara T, Takagane A, Akiya T, Takagi M, Miyashita K, Nishizaki T, Kobayashi O, Takiyama W, Toh Y, Nagaie T, Takagi S et al. S-1 plus cisplatin versus $\mathrm{S}-1$ alone for first-line treatment of advanced gastric cancer (SPIRITS trial): a phase III trial. Lancet Oncol. 2008; 9: 215-221.

16. Lenz HJ, Lee FC, Haller DG, Singh D, Benson AB, 3rd, Strumberg D, Yanagihara R, Yao JC, Phan AT, Ajani JA. Extended safety and efficacy data on S-1 plus cisplatin in patients with untreated, advanced gastric carcinoma in a multicenter phase II study. Cancer. 2007; 109: 33-40.

17. Ajani JA, Buyse M, Lichinitser M, Gorbunova V, Bodoky G, Douillard JY, Cascinu S, Heinemann V, Zaucha R, Carrato A, Ferry D, Moiseyenko V. Combination of cisplatin/S-1 in the treatment of patients with advanced gastric or gastroesophageal adenocarcinoma: Results of noninferiority and safety analyses compared with cisplatin/5-fluorouracil in the First-Line Advanced Gastric Cancer Study. Eur J Cancer. 2013; 49: 3616-3624.

18. Burotto M, Manasanch EE, Wilkerson J, Fojo T. Gefitinib and erlotinib in metastatic non-small cell lung cancer: a meta-analysis of toxicity and efficacy of randomized clinical trials. Oncologist. 2015; 20: 400-410.

19. Lv F, Liu X, Wang B, Guo H, Li J, Shen L, Jin M. S-1 monotherapy as second line chemotherapy in advanced gastric cancer patients previously treated with cisplatin/ infusional fluorouracil. Int J Clin Exp Pathol. 2014; 7: 42744279.

20. Kang YK, Kang WK, Shin DB, Chen J, Xiong J, Wang J, 
Lichinitser M, Guan Z, Khasanov R, Zheng L, Philco-Salas M, Suarez T, Santamaria J et al. Capecitabine/cisplatin versus 5-fluorouracil/cisplatin as first-line therapy in patients with advanced gastric cancer: a randomised phase III noninferiority trial. Ann Oncol. 2009; 20: 666-673.

21. Hoff PM, Saad ED, Ajani JA, Lassere Y, Wenske C, Medgyesy D, Dwivedy S, Russo M, Pazdur R. Phase I study with pharmacokinetics of S-1 on an oral daily schedule for 28 days in patients with solid tumors. Clin Cancer Res. 2003; 9: 134-142.

22. Shirao K, Hoff PM, Ohtsu A, Loehrer PJ, Hyodo I, Wadler S, Wadleigh RG, O'Dwyer PJ, Muro K, Yamada Y, Boku N, Nagashima F, Abbruzzese JL. Comparison of the efficacy, toxicity, and pharmacokinetics of a uracil/ tegafur (UFT) plus oral leucovorin (LV) regimen between Japanese and American patients with advanced colorectal cancer: joint United States and Japan study of UFT/LV. J Clin Oncol. 2004; 22: 3466-3474.

23. Maehara Y. S-1 in gastric cancer: a comprehensive review. Gastric Cancer. 2003; 6 Suppl 1: 2-8.

24. Shitara K, Sakata Y, Kudou T, Munakata M. [S-1 for gastric cancer-S-1 monotherapy and its progress]. Gan To Kagaku Ryoho. 2006; 33 Suppl 1: 43-51.

25. Wasaburo K, Tanabe S, Higuchi K, Sasaki T, Nakayama N, Mihara S, Nakatani K, Nishimura K, Shimoda T, Azuma M, Katada C, Hanaoka N, Naruke A et al. [Clinical development of S-1 (TS-1) for advanced gastric cancer]. Gan To Kagaku Ryoho. 2006; 33 Suppl 1: 57-63.

26. Quek R, Lim WT, Foo KF, Koo WH, A AM, Toh HC. Capecitabine and oxaliplatin (XELOX) is safe and effective in patients with advanced gastric cancer. Acta Oncol. 2007; 46: 1032-1034. 